\title{
Women's strategic responses to violence in Nicaragua
}

\author{
M C Ellsberg, A Winkvist, R Peña, H Stenlund
}

\begin{abstract}
Study objective-To describe the responses of women in León, Nicaragua to partner abuse and identify contextual factors associated with the use of certain coping mechanisms and the likelihood of permanent separation.
\end{abstract}

Design-Cross sectional populationbased survey.

Setting-León, Nicaragua.

Participants-188 women 15-49 years of age who had experienced physical partner abuse, out of 488 women interviewed.

Main results- $66 \%$ of women defended themselves effectively from abuse either physically or verbally. Forty one per cent of women had left home temporarily because of violence and $20 \%$ had sought help outside the home. Women experiencing severe abuse were more likely to leave or seek help, whereas women with less severe abuse were more able to defend themselves effectively. Seventy per cent of women eventually left abusive relationships. Help seeking and temporary separations increased the likelihood of a permanent separation, whereas women who defended themselves and were able to stop the violence, at least temporarily, were more likely to remain in abusive relationships.

Conclusions-Women in Nicaragua use a variety of methods in order to overcome physical partner abuse. Temporary leaving and help seeking are critical steps in the process of leaving a violent relationship. However, many women indicated that they did not receive support for their situation. More interventions are needed to help women recognise and deal with violence, as well as strengthening the community support networks available to abused women.

(F Epidemiol Community Health 2001;55:547-555)

The physical abuse of women by intimate partners is a global problem with serious consequences for the health and well being of women and children. International studies indicate that worldwide, between $20 \%-50 \%$ of women experience wife assault, and approximately $3 \%-25 \%$ of women are assaulted by partners during pregnancy. ${ }^{1-3}$ Physical abuse is often accompanied by sexual coercion, and nearly always occurs within the context of extreme jealousy and marital control. ${ }^{4-8}$ According to Dobash and colleagues, partner abuse is "often persistent and severe, occurs in the context of continuous intimidation and coercion and is inextricably linked to attempts to dominate and control women." ${ }^{\prime 9}$ The documented consequences of physical, emotional and sexual violence on women's health include chronic pain, injury, depression and suicide, and increased risk of reproductive health problems and adverse pregnancy outcomes.

Some research, primarily carried out in the United States and Europe, has investigated the extent to which women stay with abusive partners for many years despite suffering severe and often life threatening injuries. For example, one study found that $60 \%$ of women visiting a battered women's shelter in the US had returned to their husbands within six weeks after leaving the shelter, although only 34\% expressed such an intention at the time of discharge. ${ }^{10}$

Whereas some researchers have viewed the decision to stay with an abusive partner as an indicator of psychological pathology, ${ }^{11}$ most findings suggest that a woman's response to violence is shaped largely by the circumstances of the abuse and her assessment of available options. According to studies performed in the US, women who remain with their abusers have suffered less severe abuse, ${ }^{12}$ are less likely to report that their children have been physically or sexually abused by anyone ${ }^{13}$ and are more likely to say that they love their abusers. Furthermore, these women have separated from their abusers less often, are less likely to have taken legal action against their abusers, and are more likely to be financially dependent on their partners. ${ }^{14}$

Research in the US indicates that the majority of battered women do eventually leave their abusers, although they may initially try a variety of other strategies to overcome the violence, such as temporary separations, seeking outside help, and physical self defence. ${ }^{12}{ }^{15}$ Qualitative studies performed with women who have left abusive relationships suggest that overcoming violence should be viewed as a process rather than a discrete incident. ${ }^{16-18}$ Moreover, it should be noted that ending a relationship does not necessarily reduce a woman's risk, as some partners become even more violent when women leave or attempt to leave. ${ }^{7} 1920$

Landenburger presents the complex dynamic by which women become entrapped in abusive relationships and their eventual recovery as a process made up of four stages, which she refers to as binding, enduring, disengagement and recovery. ${ }^{21}$ During the binding stage violence is initially rationalised or denied, while women emphasise the positive aspects of the relationship. As violence becomes more acute and persistent, women's perceptions may change as they concentrate their efforts on 
enduring the abuse. They often "cover up" the violence, blame themselves for the abuse, and modify their own behaviour in an attempt to gain some control over the situation (for example, leaving work, not seeing friends or doing things that might make their partner angry). Eventually, many women reach a point where they are able to put a name to what is happening to them, to identify with other women in the same situation and to seek help from others. This initiates the process of disengagement and eventual recovery from the abusive relationship. Other researchers have described the early stages of abuse as a gradual process of "losing the self," whereas the process of disengagement may be viewed as a process of personal empowerment, or "regaining the self." 161722 Many women are able to describe a key event or "turning point", such as recognising the impact of the violence on their children, that motivated them to seek change.

According to this conceptual framework, a woman's awareness of and response to violence might therefore be expected to vary according to the stage of the violent relationship she is in at a given point in time. Furthermore, as Dutton points out, a woman's available options are circumscribed by many factors outside her control, including community attitudes towards violence, available resources for battered women and access to financial resources and social support. ${ }^{23}$ Therefore, the specific circumstances under which a woman is living must be taken into account in understanding her response to violence. A qualitative study of African American and Anglo American women who had left abusive relationships found that differences in cultural and social backgrounds shaped women's willingness to involve police or outside institutions, as well as their expectations and reliance on family and community structures. ${ }^{18}$

Although this topic has received relatively less attention outside North America and Europe, qualitative studies in a host of settings suggest that the barriers to leaving abusive relationships are surprisingly similar. Women cite a wide range of reasons for staying in violent relationships, including: fear of reprisals; shame and self blame; economic and emotional dependence on the abuser; concern for the children, lack of support from family and friends, and the hope that "he will change." In many countries, the stigmatising experience of being single is an additional barrier for leaving. ${ }^{15822242526}$

Once a woman decides to seek help, the response she receives plays a crucial part in determining her future actions. ${ }^{27}{ }^{28}$ Judgmental or victim blaming attitudes are likely to increase her sense of shame and self blame, and to inhibit her progress in overcoming violence. ${ }^{29}$ Unfortunately, findings from many studies around the world indicate that women who seek help for violence typically face hostility and indifference on the part of service providers, as well as a multitude of institutional and personal barriers. ${ }^{24}{ }^{30-33}$

To develop more effective interventions for women living in violent relationships, it is important to understand how women themselves are coping with violence. To date, most information on this subject is derived from qualitative studies. ${ }^{8}{ }^{15-18} 222428{ }^{34}$ Although these studies provide important insight into women's processes of change, it is difficult to generalise from these conclusions to broader populations.

The few quantitative studies have been conducted in the United States on nonrepresentative samples of battered women, usually recruited through newspaper advertisments or battered women's shelters. ${ }^{135}$ These women are likely to represent the most severely abused women. ${ }^{36}$ Consequently, little is known about those women who do not seek shelter or services who, according to most estimates, greatly outnumber those who do seek help. ${ }^{14}{ }^{37}$ Moreover, it is unclear whether findings regarding US women are relevant to women living in different social and cultural contexts.

In Nicaragua, domestic violence has been recognised as a serious and pervasive social and public health problem. Violence against women is supported by deeply rooted cultural norms that encourage women to submit to their partners' authority, and endorse the use of violence. However, in the past decade, both government and grass roots organisations have attempted to change prevailing attitudes towards violence. Over 100 centres have been set up throughout the country to provide support to battered women or to carry out educational or violence prevention programmes. ${ }^{38}$ The majority of the centres are run by local women's organisations who coordinate their actions through a broad based coalition called the National Network of Women against Violence. The Network organises yearly media campaigns on violence and in 1998 successfully lobbied to pass new legislation to protect victims of domestic violence. ${ }^{39}$ The Nicaraguan Government has also recently initiated a series of programmes to tackle domestic violence, including the introduction of 18 Comisarías de la Mujer y la Niñez (Women and Children's Police Stations) in Nicaragua's major cities. These initiatives together have led to a surge in the numbers of women reporting violence to the police, from 3000 in 1995 to over 8000 in $1997 .^{40}$ Despite this progress, the criminal justice is still weak, and the majority of cases reported to the police stations are settled out of court or dismissed. ${ }^{38} 3941$ The purpose of this research was to provide population-based data regarding how Nicaraguan women cope with abuse, and to identify contextual factors predicting women's responses to violence, including permanent separation.

\section{Methods}

The study design was a cross sectional survey carried out in 1995 in the municipality of León, Nicaragua's second largest city, with an estimated population of 200000 . The survey was performed among a representative sample of 488 women between the ages of 15 and 49 . The women were selected randomly from a cluster sample frame of 10867 women developed in 1993 for a reproductive and child health survey. ${ }^{42}$ The sampling methods and 
study design are described in detail elsewhere. ${ }^{43}$ Both quantitative and qualitative methods were used. ${ }^{44}$ Women with experiences of physical partner abuse were identified by means of the physical aggression sub-scale of the Conflict Tactics Scale. ${ }^{45}{ }^{46}$ The Conflict Tactics Scale lists eight acts according to severity. Pushing, slapping and throwing objects were classified as moderate violence, whereas kicking/hitting with a fist, blows with an object, "beating up" and threats or use of a knife or gun were classified as severe violence. Intimate partner violence was defined as the experience of one or more acts of physical violence at any time from a current or former male intimate partner. Current violence was defined as any act taking place within the 12 months before the interview.

Out of a total of 360 women who had ever been married or in common law union, 188 women, or $52 \%$ of ever married women were identified as having experienced physical violence by a partner and $27 \%$ reported physical violence in the 12 months previous to the study. ${ }^{43}$ These women were given an additional questionnaire regarding the circumstances and characteristics of abuse, including injuries, violence in pregnancy, and forced sex during violent episodes. Women were asked to recall the first and last incidents of violence, as well as their marital status both at the time of the violence and at the moment of the interview. They were further asked whether they had ever sought outside help for their situation, whether they had ever left home as a result of the violence, and whether they generally defended themselves during the violent episode. A

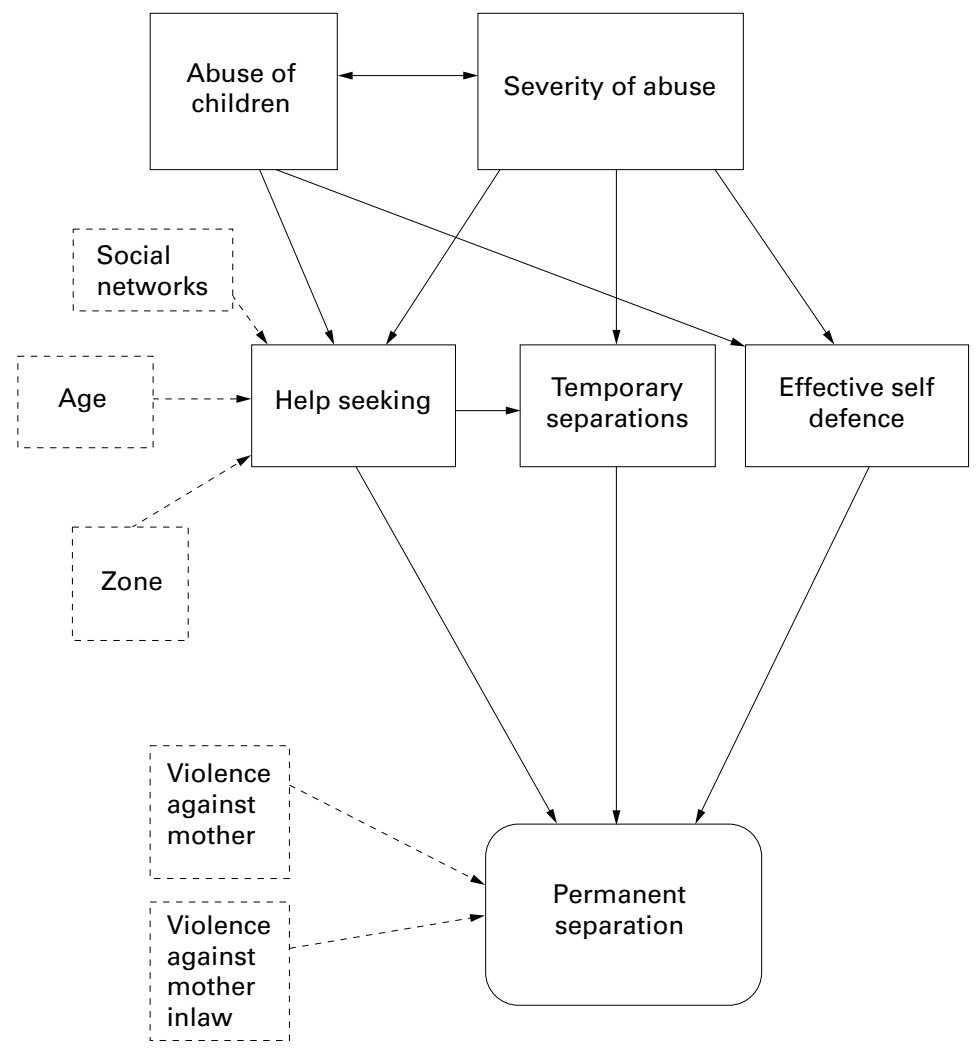

Figure 1 Hypothesised model for women's coping strategies. woman who reported defending herself was asked if the self defence was physical or verbal, and whether the violence usually stopped for the moment, got worse, or stayed the same as a result of her actions. Women were asked whether their children had ever been physically or emotionally abused by anyone, and if so, who was the perpetrator. Socioeconomic status was measured using the method of Basic Needs Assessment, which measures household access to four categories of basic sanitary, educational, and economic conditions. According to this method, which has been adapted and used widely in Nicaragua, ${ }^{42}{ }^{47}$ a household is classified as poor when there are deficits in at least one area of basic services. All interviews were carried out in complete privacy by trained female interviewers, with special measures taken to protect the safety and mental well being of both informants and interviewers. ${ }^{44}$ No woman refused to be interviewed. Educational pamphlets on domestic violence as well as referrals for free counselling were offered to all informants. Ethical clearance for the study was obtained from Nicaraguan University authorities. Random repeat interviews and logical data controls at the time of data entry were performed to control data quality.

During the analysis, considerable overlap between severe acts of physical abuse, injury, sexual abuse and violence in pregnancy was documented. Hence, a new "severity index" was created to identify those women experiencing the most severe violence through the combination of three variables indicating whether a woman had experienced forced sex (yes/no), physical violence in pregnancy (yes/no), or injuries. Injuries were coded 0 for no injuries, 1 for bruises only, and 2 for bruises and/or more severe injuries. In the new severity measure women were considered as severely abused if they scored 2 or more on a total possible scale of 4 . Child abuse was coded positive if a woman responded that one or more of her children had even been physically, sexually or emotionally abused by anyone, including herself.

Three dichotomous dummy variables were created to represent the most common coping strategies: help seeking, self defence and temporary separation. Help seeking was coded as positive if a woman had ever sought help from family, friends or more formal sources, and temporary separation was coded positive if a woman had ever left home because of partner violence and thereafter returned. Effective self defence was coded positive for women who reported that they usually defended themselves either physically or verbally and that the violent episode would usually cease, at least temporarily, when they did. Women, who reported that they never defended themselves, or if they did their husband's aggression stayed the same or got worse, were coded as 0 .

Finally, permanent separation was coded positive if the woman reported that the relationship was now over, regardless of whether or not the violence had ended. The length of time that a woman was exposed to violence in marriage (duration of violence) was estimated as years between the first violent 
Table 1 Description of the Nicaraguan women interviewed

\begin{tabular}{|c|c|c|}
\hline & $\begin{array}{l}\text { Ever married women } \\
(n=360) n(\%)\end{array}$ & $\begin{array}{l}\text { Ever abused women } \\
(n=188) n(\%)\end{array}$ \\
\hline \multicolumn{3}{|l|}{ Age } \\
\hline $15-24$ & $94(26)$ & $47(25)$ \\
\hline $25-34$ & $139(39)$ & $77(41)$ \\
\hline $35-49$ & $127(35)$ & $64(34)$ \\
\hline \multicolumn{3}{|l|}{ Education } \\
\hline 6 th grade or less & $194(54)$ & $104(55)$ \\
\hline More than 6 th grade & $166(46)$ & $84(45)$ \\
\hline \multicolumn{3}{|l|}{ Zone } \\
\hline Urban & $294(82)$ & $160(85)$ \\
\hline Rural & $66(18)$ & $28(15)$ \\
\hline \multicolumn{3}{|l|}{ Poverty } \\
\hline Non-poor & $71(20)$ & $28(15)$ \\
\hline Poor & $289(80)$ & $160(85)$ \\
\hline \multicolumn{3}{|l|}{ Number of children } \\
\hline $0-1$ & $90(25)$ & $36(19)$ \\
\hline $2-3$ & $139(39)$ & $67(36)$ \\
\hline 4 or more & $131(36)$ & $85(45)$ \\
\hline \multicolumn{3}{|l|}{ Current marital status } \\
\hline Married/common law union & $279(78)$ & $145(77)$ \\
\hline Single/separated/divorced & $81(22)$ & $43(23)$ \\
\hline \multicolumn{3}{|l|}{ Family history of violence } \\
\hline No violence in mother's family & $144(40)$ & $62(33)$ \\
\hline Violence in mother's family & $214(60)$ & $126(67)$ \\
\hline No violence in husband's family & 199 (57) & $77(41)$ \\
\hline Violence in husband's family & $144(43)$ & $98(52)$ \\
\hline \multicolumn{3}{|l|}{ Coerced sex } \\
\hline No rape & $292(81)$ & $120(64)$ \\
\hline Rape with physical abuse & $68(19)$ & $68(36)$ \\
\hline \multicolumn{3}{|l|}{ Violence in pregnancy } \\
\hline No & $304(84)$ & $132(70)$ \\
\hline Yes & $56(16)$ & $56(30)$ \\
\hline \multicolumn{3}{|l|}{ Injury } \\
\hline No injuries & $225(63)$ & $53(28)$ \\
\hline Bruises only & $101(28)$ & $101(54)$ \\
\hline Bruises and severe injuries & $34(9)$ & $34(18)$ \\
\hline \multicolumn{3}{|l|}{ Severity index } \\
\hline No violence & $172(48)$ & $0(0)$ \\
\hline Less severe (0-1 indicators) & $96(27)$ & $96(51)$ \\
\hline More severe (2-4 indicators) & $92(26)$ & $92(49)$ \\
\hline \multicolumn{3}{|l|}{ Abuse of children } \\
\hline No abuse & $265(74)$ & $120(64)$ \\
\hline Either physical or emotional abuse of one or more children & $67(19)$ & $57^{\star}(30)$ \\
\hline NA & $28(9)$ & $11(6)$ \\
\hline
\end{tabular}

incident and permanent separation or date of interview, regardless of when the last act of violence had occurred.

Multivariate logistic regression was used to evaluate factors associated with a woman's likelihood to use any of the three coping strategies, adjusting for duration of violence in all models. Thereafter, Cox's proportional hazard modelling was used to estimate the association between the length of time that women remained in a violent relationship and a series of background and contextual factors.

Both theory and the results of logistic regression and Cox regression were used to construct a hypothesised path model for predicting how the use of specific coping responses would affect women's likelihood to separate permanently (fig 1). We hypothesised that women who experienced less severe violence would have greater success in managing the situation on their own, for example by effectively defending themselves either verbally or physically. In contrast, women experiencing either severe abuse themselves, or whose children were also affected by the violence, would be more likely to seek help outside the home or to leave the house temporarily during abusive episodes. We further hypothesised that women who sought help or left the house would also be more likely to separate permanently than women who attempted to manage the violence on their own. Our model assumed that help seeking would be positively correlated to women's age, urban residence and existence of social networks, whereas the overall likelihood of leaving would be correlated also to whether there was violence in the woman's or her husband's family. Because not all parameters were significant when the full model was tested, a simplified model was created eliminating most of the exogenous variables. The simplified model will be described in the results section.

Data were analysed using SPSS 9.0 for multivariate logistic regression, life table analysis, and Cox's proportional hazard modelling. ${ }^{48}$ The fit of our hypothesised path model was tested using Amos software 3.6. ${ }^{49}$ Statistical significance was assessed by means of $95 \%$ confidence intervals and two tailed $\mathrm{p}$ values $<0.05$.

\section{Results}

RESISTANCE: WOMEN'S STRATEGIC RESPONSES TO VIOLENCE

All 360 ever married women interviewed and the 188 women who experienced physical partner abuse are presented in table 1 . Women who experienced abuse were more likely to live in the urban area, to be poor, and to have more

Table 2 Description of battered women's responses to violence $(n=188)$

\begin{tabular}{ll}
\hline & $n(\%)$ \\
\hline Self defence & \\
No self defence & $29(16)$ \\
Self defence/violence is same or worse & $34(18)$ \\
Effective self defence (violence ends) & $123(66)$ \\
Temporary separations & \\
No separations & $111(59)$ \\
At least one temporary separation & $77(41)$ \\
Help seeking & $150(80)$ \\
Does not seek outside help & $38(20)$ \\
Seeks outside help & \\
Visits to institutions for help & \\
Police & $28(14)$ \\
Women's house & $11(6)$ \\
Hospital & $10(5)$ \\
Health centre & $4(2)$ \\
Permanent separation & $116(62)$ \\
Yes & $72(38)$ \\
\hline$\star$
\end{tabular}

^Answers do not add up to $100 \%$ because of multiple responses.

Table 3 Factors associated with help seeking among 160 urban women with lifetime experiences of physical partner abuse ${ }^{\star}$

\begin{tabular}{lll}
\hline & $\begin{array}{l}\text { Crude odds } \\
\text { ratios (95\% CI) }\end{array}$ & $\begin{array}{l}\text { Adjusted odds } \\
\text { ratios (95\% CI)t }\end{array}$ \\
\hline Age & 1.0 & 1.0 \\
$15-24$ & $2.4(0.7,7.7)$ & $1.9(0.4,8.3)$ \\
$25-34$ & $3.9(1.2,12.6)$ & $4.7(0.9,24.8)$ \\
$35-49$ & 1.0 & 1.0 \\
$\begin{array}{l}\text { Abuse of children } \\
\text { No abuse }\end{array}$ & $6.6(2.9,14.7)$ & $5.7(2.3,14.2)$ \\
$\begin{array}{l}\text { Abuse } \\
\text { Social networks }\end{array}$ & 1.0 & 1.0 \\
$\begin{array}{l}\text { No support } \\
\text { Family and/or instrumental } \\
\quad \text { support }\end{array}$ & $2.5(0.8,7.7)$ & $5.3(1.4,20.6)$ \\
$\begin{array}{l}\text { Severity } \\
0-1\end{array}$ & 1.0 & 1.0 \\
$2-4$ & $6.3(2.6,15.6)$ & $9.4(3.3,26.9)$ \\
\hline
\end{tabular}

* Only urban women are included in the model as all women seeking help were from the urban area. †All four variables included in the model, with adjustment for duration of relationship $-2 \log$ likelihood statistic on $6 \mathrm{df}=129.835 \mathrm{p}<0.000$. 


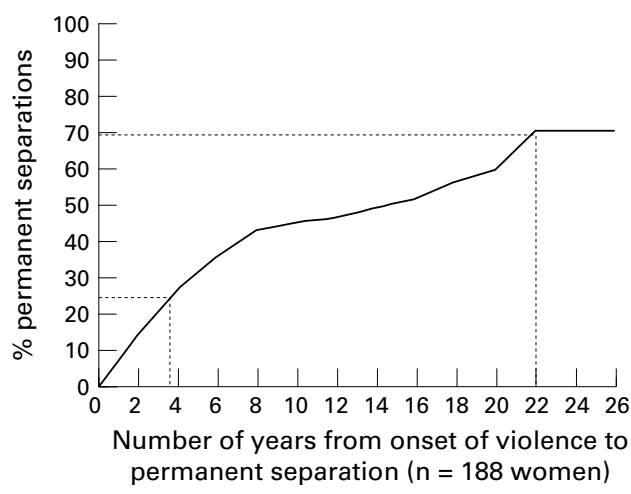

Figure 2 Probability of separation over time in violent relationships, based on Kaplen-Meier life table analysis.

than four children than women not experiencing abuse. They were also more likely to report that their mothers or their mothers in law had been physically abused by a partner. ${ }^{43}$

Abused women reported using different strategies to cope with the violence (table 2). The most common strategy for dealing with violence was physical or verbal self defence, mentioned by $84 \%$ of abused women. Among these women $78 \%$ reported that the violence usually ceased as a result, at least temporarily. Forty one per cent of women had separated temporarily from their partner as a result of violence, whereas only $20 \%$ of women had ever sought outside help. Only $7 \%$ of women had not tried any of the three strategies, whereas $51 \%$ had tried only one, and $42 \%$ had tried two or more different strategies. Thirty eight per cent of women had permanently separated from their partners at the time of the interview, whereas $62 \%$ were still living with the abusive partner.

Among 116 women who were still living with the abusive partner at the time of the interview, $40 \%$ (46) had experienced physical violence within the 12 months before the interview and $84 \%$ (97) of women had experienced violence within the last four years. Among 72 women who had left the abusive partner, $85 \%$ of women (61) reported that the last incident of abuse occurred during or before the year of separation. Although $19 \%$ (14) reported that the last incident of violence occurred after they were separated, a smaller number $(13 \%, n=9)$ reported that the last incident of violence occurred more than 12 months after separation.

In multivariate logistic regression analysis of factors associated with the use of different coping strategies, significant negative associations were found between effective self defence and severity of abuse $(\mathrm{OR}=0.5,95 \% \mathrm{CI} 0.3,1.0)$ as well as abuse of children $(\mathrm{OR}=0.5$, $95 \% \mathrm{CI}=0.3,0.9)$. Temporary separations were positively associated with severity of abuse $(\mathrm{OR}=1.7,95 \% 1.0,3.1)$. Finally, help seeking was significantly associated with severe abuse, physical or emotional abuse of children, being over 35 years of age and access to social support at the bivariate level (table 3). All women who sought help for violence lived in the urban area. In the multivariate model the
KEY POINTS

- Nicaraguan women use a variety of strategies to cope with domestic violence, according to how severe they perceive the abuse to be.

- Leaving an abusive relationship is a process, not a one time event.

- Seeking outside help and temporary separations are critical steps in the process of overcoming violence.

- Community and family support can help women recognise and overcome domestic violence.

association between age and help seeking was not significant.

No associations were found between age, zone or social support with either temporary separation or effective self defence. No associations were found between poverty, education, number of children or marital status and any of the three coping mechanisms. No interactions were found between different coping strategies and age or urban/rural residence.

When asked in open-ended questions what kind of support they would have liked, $40 \%$ of women said they would have liked to have "psychological counselling", "someone to give me advice" or "someone to stand up for me." An additional $13 \%$ desired more family support, and $10 \%$ counselling for their husbands. When asked why they didn't receive the help they needed, the most common answer was "because I was alone" or "because I didn't know how to find it." Moreover, $41 \%$ of battered women indicated that their husbands threatened to hurt or kill them or to take away their children, if they reported the violence.

Of those women who actually left violent relationships $50 \%$ eventually remarried nonviolent men. Only $13 \%$ of ever-battered women interviewed reported having had a violent relationship with more than one man. When asked, "Do you expect something similar to happen again?" $39 \%$ said yes, while $37 \%$ said no. Women currently in violent relationships were more likely to respond positively

Table 4 Factors influencing how long women stay in violent relationships. In women aged 15-49 $(n=188)$. Univariate and multivariate hazards ratios $(H R)$ and 95\% confidence intervals (CI) are presented by means of Cox survival analysis, indicating the relative risk of leaving a relationship soon after violence begins. Values over 1.0 indicate more rapid separation compared with values under 1.0

\begin{tabular}{lll}
\hline Variable & $\begin{array}{l}\text { Bivariate HR } \\
(95 \% \mathrm{CI})\end{array}$ & $\begin{array}{l}\text { Multivariate } \\
\text { HR }(95 \% \mathrm{CI})\end{array}$ \\
\hline Age group & 1.0 & \\
$\quad 15-24$ & $0.6(0.32,1.1)$ & $0.5(0.3,0.9)$ \\
$25-34$ & $0.4(0.2,0.8)$ & $0.4(0.2,0.9)$ \\
$35-49$ & 1.0 & 1.0 \\
Husband's mother not abused & $0.5(0.3,0.8)$ & $0.6(0.4,1.1)$ \\
Husband's mother abused & 1.0 & 1.0 \\
Wife's mother not abused & $0.6(0.4,1.0)$ & $0.6(0.4,1.0)$ \\
Wife's mother abused & 1.0 & 1.0 \\
Primary or less & $1.7(1.1,2.7)$ & $1.7(1.0,2.8)$ \\
High school & 1.0 & 1.0 \\
No temporary separation & $1.8(1.1,2.9)$ & $2.0(1.2,3.3)$ \\
Temporary separation & 1.0 & 1.0 \\
No self defence & $0.5(0.3,0.8)$ & $0.6(0.4,0.9)$ \\
Effective self defence &
\end{tabular}

-2 Log likelihood statistic on $7 \mathrm{df}=570.546 \mathrm{p}<0.000$. 
Table 5 Goodness of fit measures for path models

\begin{tabular}{llllllll}
\hline & $\begin{array}{l}\text { Normed fit } \\
\text { index (NFI) }\end{array}$ & $\begin{array}{l}\text { Goodness of fit } \\
\text { index (GFI) }\end{array}$ & $\begin{array}{l}\text { Adjusted GFI } \\
(\text { AGFI) }\end{array}$ & $\begin{array}{l}\text { Root mean square error of } \\
\text { approximation (RMSEA) }\end{array}$ & $\begin{array}{l}\text { Root mean } \\
\text { residual (RMR) }\end{array}$ & $\chi^{2} /$ df ratio & $p$ \\
\hline Model 1 & 0.63 & 0.94 & 0.90 & 0.06 & 0.02 & 1.74 \\
Model 2 & 0.93 & 0.99 & 0.97 & 0.00 & 0.01 & 0.84 & 0.00 \\
Desired & $>0.90$ & $>0.90$ & $>0.90$ & $<0.08$ & $<0.05$ & $<3.0$ & $>0.05$ \\
\hline
\end{tabular}

Table 6 Correlation matrix for variables included in models 1 and 2. Spearman correlation's coefficients are presented with corresponding significance levels

\begin{tabular}{|c|c|c|c|c|c|c|c|c|c|c|c|}
\hline & Severity & $\begin{array}{l}\text { Temporary } \\
\text { separation }\end{array}$ & $\begin{array}{l}\text { Effective } \\
\text { self defence }\end{array}$ & $\begin{array}{l}\text { Looks for } \\
\text { help }\end{array}$ & $\begin{array}{l}\text { Permanent } \\
\text { separation }\end{array}$ & $\begin{array}{l}\text { Violence } \\
\text { against mother }\end{array}$ & $\begin{array}{l}\text { Violence against } \\
\text { mother in law }\end{array}$ & Zone & $\begin{array}{l}\text { Social } \\
\text { networks }\end{array}$ & Age & $\begin{array}{l}\text { Abuse of } \\
\text { children }\end{array}$ \\
\hline Severity & 1.00 & $0.19^{\star}$ & $-0.21^{\star \star}$ & $0.33^{\star \star}$ & 0.12 & 0.04 & -0.01 & -0.09 & -0.13 & -0.02 & $0.15^{\star}$ \\
\hline Temporary separation & & 1.00 & -0.12 & $0.15^{\star}$ & $0.23^{\star \star}$ & 0.08 & -0.07 & 0.14 & -0.06 & 0.03 & 0.04 \\
\hline Effective self defence & & & 1.00 & -0.06 & $-0.23^{\star \star}$ & 0.13 & -0.07 & 0.02 & -0.03 & $0.15^{\star}$ & -0.13 \\
\hline Looks for help & & & & 1.00 & $0.20^{\star \star}$ & -0.01 & -0.02 & $0.21^{\star \star}$ & 0.11 & $0.20^{\star \star}$ & $0.36^{\star \star}$ \\
\hline Permanent separation & & & & & 1.00 & $-0.17^{\star}$ & $-0.19^{\star}$ & $0.18^{\star}$ & -0.09 & 0.04 & 0.12 \\
\hline Violence against mother & & & & & & 1.00 & $0.23^{\star \star}$ & 0.09 & -0.03 & -0.02 & -0.08 \\
\hline Violence against mother in law & & & & & & & 1.00 & -0.05 & -0.06 & 0.05 & $0.17^{\star}$ \\
\hline Zone & & & & & & & & 1.00 & -0.05 & $0.15^{\star}$ & 0.02 \\
\hline Social networks & & & & & & & & & 1.00 & 0.04 & -0.03 \\
\hline Age & & & & & & & & & & 1.00 & $0.25^{\star \star}$ \\
\hline Abuse of children & & & & & & & & & & & 1.00 \\
\hline
\end{tabular}

${ }^{\star \star}$ Correlation is significant at the 0.01 level (two tailed). ${ }^{\star}$ Correlation is significant at the 0.05 level (two tailed).

$(52 \%)$. However, even among women who had permanently separated from their violent spouse, $34 \%$ still believed that they would eventually be beaten again.

\section{BREAKING AWAY: THE PATH TO PERMANENT} SEPARATION

Approximately $25 \%$ of the women left the abusive relationship within the first four years after the violence began (fig 2). Overall, approximately $70 \%$ of women were likely to separate eventually from their abusive partners while another 30\% remained in violent relationships as long as 26 years, which was the maximum extent of follow up.

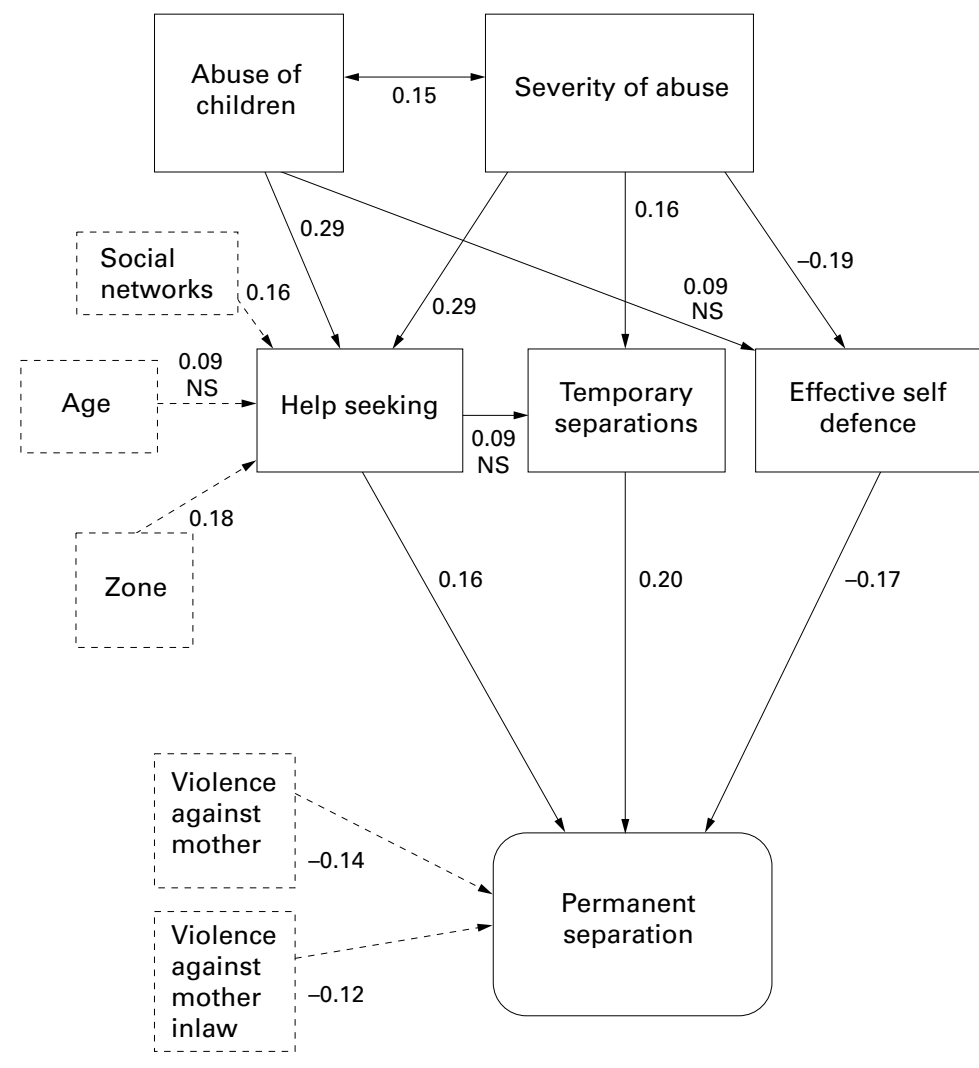

Figure 3 Estimates of path coefficients of hypothesised model.
No associations were found between the rate at which women ended relationships and the severity of violence, help seeking, mental health status, abuse of children, poverty, zone and the existence of social networks or previous victimisation.

Women under 25 years of age, with more than a 6 th grade education, and women with no history of violence in their own or their husband's families permanently separated from their partner more quickly than women without these characteristics (table 4). Women who had left temporarily also were significantly more likely to make a final break more rapidly. Women who defended themselves effectively were likely to remain longer in abusive relationships.

Finally, structural equation modelling techniques were used to estimate and to assess the fit of the hypothesised path model relating severity of abuse, women's coping responses and permanent separation. Because there is no consensus regarding a single best measure for goodness of fit, ${ }^{50}$ several measures were used and these are presented in table 5 . The ratio of $\chi^{2}$ to degrees of freedom was $1.74(<3.0$ is desirable), and the goodness of fit index (GFI) was 0.94 on a scale from $0-1.0$ where the best fit is closest to 1. All parameters measured indicated an acceptable fit, with the exception of the normed fit endex (NFI), which measures the improvement in goodness of fit between the hypothesised model as compared with an independence model. The overall model yielded a goodness of fit of $\chi^{2}(40)=69.5$ with a $p$ value of 0.003 (fig 3). Because a rejection of the null hypothesis indicates that the model does not fit the data, in our case a non-significant $p$ value was desirable. The corresponding correlation matrix is presented in table 6 .

We decided also to test the fit of a simplified model by eliminating all of the exogenous variables (that is, age, social networks, zone, and family history of violence) with the exception of severity of abuse and abuse of children. The two non-significant pathways (abuse of children and effective self defence as well as help 


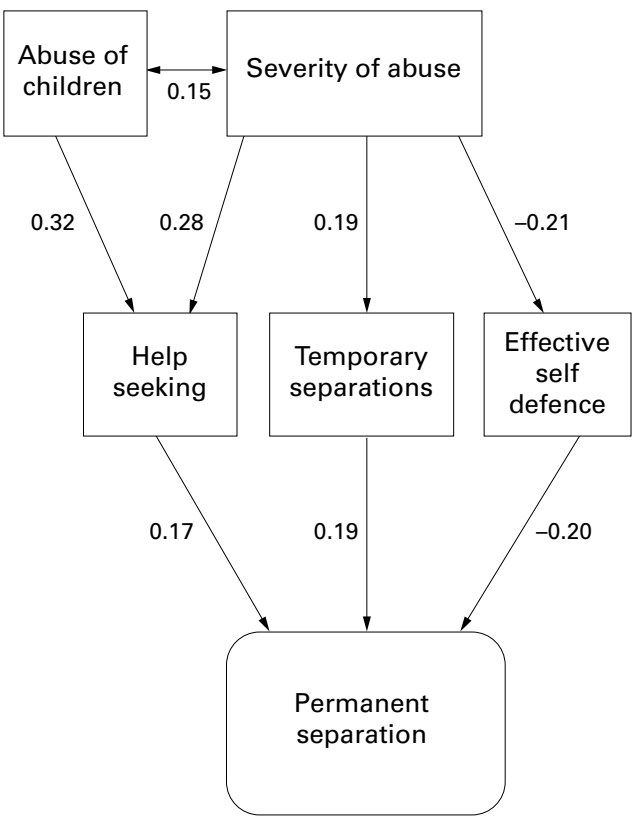

Figure 4 Estimates of path coefficients for simplified model.

seeking and temporary separations) were also eliminated. The simplified model yielded a fit of $\chi^{2}(7)=5.9$, with a $\mathrm{p}$ value of 0.55 (fig 4). The ratio of $\chi^{2}$ to degrees of freedom was 0.84 . All correlations among the variables of the path model were significant and all measures of goodness of fit were greatly improved (see fig 4).

According to this model, severe abuse increases the likelihood that a woman will seek outside help and/or leave the home temporarily. The abuse of children also increases a woman's likelihood to seek help. These responses in turn predicted her likelihood to eventually separate from her partner permanently. In contrast, less severely abused women were more likely to defend themselves and to stop the violence. Women who were able to defend themselves effectively, even temporarily, were more likely to remain with their partners.

\section{Discussion}

Our findings indicate that a significant proportion of Nicaraguan women suffer severe physical and sexual violence by intimate partners, including during pregnancy. Most women eventually separate permanently from their abusers, although they may try a variety of coping strategies first. In contrast with the common portrayal of abused women as passive victims, most women actively attempt to "manage" the violence using a variety of strategies, according to how dangerous they perceive the situation to be. When abuse is less severe, women are more likely to defend themselves verbally or physically, and are often able to end the violent episode, at least temporarily. These women are likely to remain with a violent partner for a longer period of time.

When violence becomes severe, as represented in our study by injuries, violence during pregnancy or coerced sex, or when their children are also abused, women seek alternative means to manage the situation by seeking help or escaping temporarily. These women were also more likely eventually to separate permanently from their partners. Thus, severity of violence seems to influence permanent separation through its effect on the intervening coping strategies, for example, help seeking and temporary separations. These findings are consistent with international research indicating that disclosure and reaching out to others for help are critical steps along the pathway of change for abused women. ${ }^{285}$ A Canadian study also found that women's age and the severity of violence she experienced were predictors for seeking help with formal services. $^{52}$

Qualitative research suggests that a woman's decision to seek help may be triggered by a specific incident, and is often motivated by the recognition of how her children are affected by the violence. ${ }^{21}$ One woman from our study area explicitly described recognising the impact of her husband's violence on her daughters as a turning point in her decision to end her marriage. ${ }^{44}$

Our findings indicate, however, that the vast majority of abused women do not seek outside help, and many do not receive the kind of support or services they need. The associations found between different responses and social and family support, as well as a history of violence in the family suggest the importance of the family and social context for shaping women's view of their options. Women who have witnessed violence against their mothers, or whose husbands were raised in violent homes may be more likely to consider violence as an inevitable part of marital life. Qualitative research in the same study area indicated that many women feel social pressure to endure violence quietly to keep the family together. "Do you think you're the only one to live through this?" and "You have to maintain your marriage, remember that he is your husband and the father of your children," were examples of common reactions on the part of mothers and mothers in law to the violence. One battered woman who went to the police, reported that the police not only ignored her pleas for help but gave the husband a ride back home, where he subsequently beat her up again the same night. ${ }^{44}$

These findings are consistent with population-based findings from the United States, Egypt, Canada, Chile and Cambodia. In these studies, less than half the battered women had ever told anyone about the violence before the survey. Those who had, primarily told family members and friends. Only a minority of the women surveyed had ever contacted the police. ${ }^{1}{ }^{75-55}$

Residency also affected a woman's alternatives for coping with violence. Not a single rural woman from our sample reported having sought help through formal channels despite suffering severe violence. This probably reflects rural women's limited access to services rather than reluctance to seek help. Most police stations for women and women's centres in 
Nicaragua are located in the urban areas, and may be out of reach to rural women. Unfortunately, because of the small size of the rural group, it was not possible to carry out more in depth stratified analysis.

In contrast with popular opinion, we found that women who managed to leave violent relationships did not usually get involved again with a violent partner. However, many women, even after having left a violent partner years earlier, still believed that they would be beaten again. This finding indicates that the fear and emotional sequelae of abuse may persist much longer than the actual risk of physical violence.

A strength of this study is that it was performed on a population-based sample of women who had experienced partner abuse. Because León shares general demographic characteristics with the rest of the country, it is probable that these findings are representative of the experiences of abused women throughout Nicaragua. However, because of the cross sectional design of the study, there are some potential sources of bias that should be investigated.

For example, as Landenburger points out, women may have a different perception of the violence according to what stage she is in with respect to disengagement. ${ }^{21}$ This could potentially affect the results if women who had already left an abusive relationship were more likely to report being severely abused than women who were still with their abusers. However, the fact that no direct association was found between reported severity of violence and current relationship status indicates that this was probably not a problem in our research.

Our model estimates duration of a violent relationship as the time from the first incident of violence up to either permanent separation or the time of the interview. The main weakness of this method is that it assumes that the risk of violence continues throughout the relationship regardless of when the last incident of violence occurred. It also assumes that violence ends once the relationship is over, which is often not the case. In fact, some studies have found that the risk of violence may increase once a woman decides to separate from her partner. ${ }^{19}$ However, we believe that our method provides a reasonable approximation of violence duration, as the great majority of women in our sample had experienced partner abuse up to the time of separation or within the last four years before the interview. Moreover, we found that the timing of the last incident of violence did not always determine whether a woman felt that the violence was over. Qualitative research might provide greater insight as to the factors affecting women's perceptions of safety.

Some apparent discrepancies were observed in the results obtained using different statistical methods. For example, help seeking was positively correlated to permanent separation in the path analysis, but not in the Cox proportional hazards modelling. Using path analysis, we addressed the overall fit of the model and the plausibility of causal pathways between a variety of variables. Cox regression, on the other hand, uses only one dependent variable and incorporates the concept of time. We used Cox regression modelling, therefore, to predict not only who is more likely to ever separate permanently, but also the rate at which they will separate.

It is encouraging that younger women, on the whole, seem to be less tolerant of partner violence and more willing than women of their mothers' generation to end a relationship as soon as it becomes violent. This difference is probably because of a cohort or time effect, reflecting the changes in cultural attitudes and resources for abused women in Nicaragua during the past 30 years. During the 1980s, when Nicaragua was governed by the revolutionary Sandinista party, women were encouraged to educate themselves and to participate in social and economic development. The promotion of gender equity was also a stated goal of the Sandinista government, although specific resources for battered women violence were limited.

During the 1990s, despite the election of two conservative governments, there was an enormous increase in the number of both governmental and non-governmental services for battered women, as well as national media campaigns against violence. ${ }^{56} \mathrm{~A}$ qualitative study of survivors of abuse attending a local women's centre found that many women's perceptions and actions were transformed as a result of their participation. The women felt that their experiences had increased not only their knowledge of legal rights, and their feelings of self worth, but also their ability to identify and deal with abuse, and their commitment to helping other women in similar situations. ${ }^{38}$ A recent Demographic and Health Survey carried out in Nicaragua found that $49 \%$ of reproductive age women had heard a message on violence on the radio or $\mathrm{TV}$, and $20 \%$ of women were able to repeat at least one of the messages. ${ }^{56}$ These messages are likely to have had a profound influence of women living with violence, by indicating that violence is not acceptable, and that it is no longer a private or shameful subject. This, together with an increase in specialised services, may account for the surge in women seeking help in recent years. The present research findings were also publicised extensively in Nicaragua, and were used by the women's anti-violence movement in a successful campaign for legislative reform on domestic violence. ${ }^{39}$

Our research is consistent with other studies in highlighting the crucial part that families and the immediate community play by enabling or frustrating women's attempts to overcome violence. Therefore, strengthening community support networks could make an important contribution to preventing domestic violence. Another priority intervention area would be to improve the response of service providers and legal and health institutions so that when women do decide to reach out for help they receive appropriate and timely support. 
The authors gratefully acknowledge the valuable comments of Lori Heise, Stig Wall, Jerker Liljestrand and Lars Åke Persson on earlier drafts of this paper.

Funding: this research was provided with funding by Umeå University and the Swedish Agency for International Development Cooperation (Sida).

Conflicts of interest: none. 1 Heise L, Ellsberg M, Gottemoeller M. Ending violence 2 Campbell JC, Lewandowski LA. Mental and physical health effects of intimate partner violence on women and effects of intimate partner violence on women
children. Psychiatr Clin North Am 1997;20:353-74.

3 Gazmararian JA, Lazorick S, Spitz AM, et al. Prevalence of violence against pregnant women. $\mathcal{F} A M A$ 1996;275:191520.

4 Schuler SR, Hashemi SM, Riley AP, et al. Credit programs, patriarchy and men's violence against women in rura Bangladesh. Soc Sci Med 1996;43:1729-42.

5 Armstrong A. Culture and choice: lessons from survivors of gender violence in Zimbabwe. Harare: Violence Against Women In Zimbabwe Research Project, 1998.

6 Johnson H. Dangerous domains: violence against women in Canada. Ontario, Canada: International Thomson Publishing, 1996.

7 Tiaden P, Thoennes N. Extent, nature and consequences of intimate partner violence: Findings from the National Violence Against Women Survey. Washington, DC: National Institute of Justice, Centers for Disease Control and Prevention, of Jus 2000.

8 Zimmerman K. Plates in a basket will rattle: domestic violence in Cambodia, a summary. Phnom Penh, Cambodia: Project Against Domestic Violence, 1995.

9 Dobash R, Dobash R, Wilson M, et al. The myth of sexual symmetry in marital violence. Social Problems 1992;39:7191.

10 Snyder DK, Fruchtman LA. Differential patterns of wife abuse: a data-based typology. F Consult Clin Psychol 1981;49:878-85.

11 Bergman B. Battered Women: Why are they battered and why do they stay? ] [PhD thesis]. Stockholm: Karolinska, 1990.

12 Jacobson NS, Gottman JM, Gornter E, et al. Psychological factors in the longitudinal course of battering. When do the couples split up? When does the abuse decrease? Violence Vict 1996;11:371-92.

13 Rounsaville BJ. Battered wives: barriers to identification and treatment. Am f Orthopsychiatry 1978;48:487-94.

14 Strube M. The decision to leave an abusive relationship: empirical evidence and theoretical issues. Psychol Bull empirical evidence

15 Campbell J, Rose L, Kub J, et al. Voices of strength and resistance: a contextual and longitudinal analysis of women's responses to battering. Fournal of Interpersonal Violence 1998;13:743-62.

16 Meritt-Gray M, Wuest J. Counteracting abuse and breaking free: the process of leaving revealed through women's voices. Health Care for Women International 1995;16:399412.

17 Mills T. The assault on the self: Stages in coping with battering husbands. Qualitative Sociology 1985;8:103-23.

18 Moss VA, Pitula CR, Campbell JC, et al. The experience of terminating an abusive relationship from an anglo and african american perspective: a qualitative descriptive study. Issues Ment Health Nurs 1997;18:433-54.

19 Kyriacou DN, Anglin D, Taliaferro E, et al. Risk factors for injury to women from domestic violence against women. $N$ Engl f Med 1999;341:1892-8.

20 Campbell J. Assessing dangerousness: violence by sexual offenders, batterers, and child abusers. Thousand Oaks, CA: Sage ers, batterers, and child

21 Landenburger K. A process of entrapment in and recovery from an abusive relationship. Issues Ment Health Nurs 1989; 10:209-27.

22 Kirkwood C. Leaving abusive relationships. London: Sage, 1992.

23 Dutton MA. Battered women's strategic response to violence: the role of context. In: Edelson JL, Eisikovits ZC, eds. Future interventions with battered women and their families. London: Sage, 1996.

24 Pan-American Health Organization (PAHO). Ruta critica que siguen las mujeres victimas de violencia intrafamiliar: Análisis y resultados de investigación. [Help seeking by Analisis y rasultados de investigacion. [Help seeking by vand research results]. Panama City: Organización Panamericana de la Salud en

Rao V. Wife-beating in rural South India: a qualitative and econometric analysis. Soc Sci Med 1997;44:1169-79.
26 Walker L. The battered woman. New York: Harper and Row, 1979.

27 Fawcett GM, Heise L, Isita-Espejel L, et al. Changing community responses to wife abuse: A research and demonstration project in Iztacalco, Mexico. Am Psychologist 1999;54: $41-9$

28 Brown J. Working toward freedom from violence. fournal of Violence Against Women 1997;3:5-26.

29 Janoff-Bulman R, Frieze IH. A theoretical perspective for understanding reactions to victimisation. Fournal of Social Issues 1983;39:1-17.

30 Prasad S. Medio-legal response to violence in India. Violence against Women 1998;5:478-506.

31 Watts C, Ndlovu M. Addressing violence in Zimbabwe: Strengthening the health sector response. In: Musasa Project. Violence against women in Zimbabwe: strategies for action. Harare, Zimbabwe: Musasa Project, 1997.

32 Rodriguez MA, Quiroga SS, Bauer HM. Breaking the silence: Battered women's perspectives on medical care. Arch Fam Med 1996;5:153-8.

33 Warshaw C. Domestic violence: changing theory, changing practice. F Am Med Womens Assoc 1996;51:87-91, 100.

34 Barnett O, LaViolette A. It could happen to anyone: why battered women stay. Newbury Park: Sage Publications, 1993.

35 Campbell J, Soeken K. Women's responses to battering over time: an analysis of change. F Interper Violence 1999;14:21-

36 Johnson M. Patriarchal terrorism and common couple violence: two forms of violence against women. 7 Marriage Fam 1995;57:283-94

37 Sorenson SB, Saftlas AF. Violence and women's health. The role of epidemiology. Ann Epidemiol 1994;4:140-5.

38 Wessel L, Campbell J. Providing sanctuary for battered women: Nicaragua's Casas de la Mujer. Issues Ment Health Nurs 1997;18:455-76.

39 Ellsberg M, Liljestrand J, Winkvist A. The Nicaraguan Network of Women against Violence: using research and action for change. Reproductive Health Matters 1997;10:82-92.

40 Policía Nacional. Violencia física y sexual contra la mujer. [Physical and sexual violence against women]. Managua, Nicaragua: Policía Nacional, 1997.

41 Ellsberg M, Caldera T, Herrera A, et al. Domestic violence and emotional distress among Nicaraguan women: results from a population-based study. Am Psychologist 1999;54: 30-6.

42 Peña R, Liljestrand J, Zelaya E, et al. Fertility and infant mortality trends in Nicaragua 1964-93. The role of women's education. F Epidemiol Community Health 1999;53: 132-7.

43 Ellsberg MC, Peña R, Herrera A, et al. Wife abuse among women of childbearing age in Nicaragua. Am $\mathcal{f}$ Public Health 1999;89:241-4

44 Ellsberg M, Peña R, Herrera A, et al. Candies in hell: women's experiences of violence in Nicaragua. Soc Sci Med 2000;51:1595-610.

45 Straus MA, Gelles RJ. Measuring intrafamily conflict and violence: The Conflict Tactics (CT) Scale. 7 Marriage Fam 1979;41:75-88.

46 Straus MA, Gelles RJ. Societal change and change in family violence from 1975 to 1985 as revealed by two national surveys. f Marriage Fam 1986; 48:465-80.

47 Renzi MR, Agurto S. La Esperanza Tiene Nombre de Mujer. [Hope is a woman's name]. Managua: Fideg, 1998.

48 Statistical Package for Social Sciences. SPSS. 9.0 ed. Chicago: SPSS, 1999

49 Arbuckle JL. AMOS. 3.6 ed. Chicago: Small Waters Corporation, 1997.

50 Maruyama GM. Basics of structural equation modeling. Thousand Oaks: Sage Publications, 1998.

51 Short LM, McMahon PM, Dawkins N. Survivors' identification of protective factors and early warning signs for intimate partner violence. Violence against Women 2000;6:272-

52 Johnson H. Social control and the cessation of assaults on wives. [PhD thesis]. Manchester: University of Manchester, 1998.

53 Larrain SH. Violencia Puertas Adentro: La Mujer Golpeada. [Violence behind closed doors: battered women]. Santiago, Chile: Editorial Universitaria, 1994

54 Nelson E, Zimmerman C. Household survey on domestic violence in Cambodia. Phnom Penh, Cambodia: Ministry of Women's Affairs and Project Against Domestic Violence, 1996.

55 El-Zanaty F, Hussein EM, Shawky GA, et al. Egypt Demographic and Health Survey 1995. Calverton, MD: Macro International, 1996.

56 Rosales J, Loaiza E, Primante D, et al. Encuesta Nicaraguense de Demografia y Salud, 1998. Managua, Nicaragua: Instituto Nacional de Estadisticas y Censos, INEC, 1999. 